\title{
CONTROLE DO ASSOREAMENTO E DOS CONTAMINANTES POR MEIO DA GESTÃO DE BACIAS HIDROGRÁFICAS PARA O PLANEJAMENTO DAS DRAGAGENS PORTUÁRIAS NA BAÍA DE ANTONINA/PARANÁ/BRASIL
}

\section{Watershed management for controlling the silting and contaminants to plan for the dredging of the ports in Antonina Bay - Paraná - Brazil}

\author{
Eduardo Vedor de PAULA ${ }^{1}$ \\ Camila CUNICO ${ }^{2}$ \\ Eliane Beê BOLDRINI ${ }^{3}$
}

\begin{abstract}
RESUMO
A ameaça de inviabilização das atividades portuárias, em função dos custos com dragagens de manutenção, como o caso dos Terminais Portuários da Ponta do Félix, torna necessária a investigação da origem do processo de assoreamento, bem como dos contaminantes presentes nos sedimentos na Baía de Antonina, situada no litoral do Estado do Paraná. Foi objetivo desta etapa da pesquisa, desenvolvida no âmbito do Programa CAD, caracterizar os aspectos físico-naturais relevantes que auxiliam na investigação e compreensão do crescente assoreamento dessa baía, cuja área de drenagem totaliza $1.621,5 \mathrm{~km}^{2}$.
\end{abstract}

\section{Palavras-chave:}

Assoreamento; contaminantes; gestão de bacias hidrográficas; planejamento de dragagens; Baía de Antonina/PR.

\begin{abstract}
The threat of port activities becoming unfeasible due to maintenance dredging costs, as is the case of the Port Terminals of Ponta do Felix, makes it necessary to investigate the origins of the silting process, as well as of the contaminants that are present in the sediments found in the Antonina Bay, located at the coastline of the Sate of Paraná. The purpose in this part of the research, developed within the CSD Programme, was to characterize the relevant physical-natural aspects that could help in the investigation and understanding of the growing silting in this bay, which has drainage area that totals $1,621.5 \mathrm{~km}^{2}$.
\end{abstract}

\section{Key-words:}

Silting; contaminants; watershed management; planning for dredging; Antonina Bay/PR.

\footnotetext{
1 Professor Msc. Substituto do Depto. de Geografia da UFPR. Pesquisador da Associação de Defesa do Meio Ambiente e do Desenvolvimento de Antonina (Ademadan). Doutorando do Programa de Pós-Graduação do Depto. de Geografia da UFPR (bolsista Capes).

2 Pesquisadora da Ademadan. Mestranda do Programa de Pós-Graduação do Depto. de Geografia da UFPR (bolsista Capes).

${ }^{3}$ Coordenadora do Programa de Gestão Socioambiental Portuária das Faculdades Integradas Espírita - Campus de Antonina; Pesquisadora da Ademadan; Consultora Ambiental dos Terminais Portuários da Ponta do Félix; Doutora em Educação (UFPR).
} 


\section{INTRODUÇÃO}

A necessidade de constantes dragagens para a segurança da navegação portuária configura o principal aspecto ambiental de impacto negativo das atividades portuárias em todo o mundo, demonstrando-se consideravelmente onerosa e motivo de conflitos sociais, políticos e econômicos entre os terminais privados, as autoridades portuárias, os órgãos ambientais, as ONGs e a comunidade acadêmica, o que dificulta extremamente o processo de licenciamento ambiental. A essa realidade deve-se ser somado o fato de que os sedimentos dragados, em geral, apresentam-se contaminados por metais pesados, hidrocarbonetos entre outras formas de poluição.

No caso do Porto de Antonina, mais precisamente dos Terminais Portuários da Ponta do Félix (TPPF), o qual é subordinado à Administração dos Portos de Paranaguá e Antonina (Appa) e constitui-se num terminal privado de uso público, cujos acionistas representam fundos nacionais de pensão, a questão do assoreamento dos berços, da bacia de evolução e dos canais de acesso é um processo crítico que exige constantes dragagens de manutenção. Razão pela qual, para garantir calado aos navios, a manutenção da profundidade das áreas de navegação se torna extremamente onerosa para o empreendimento e para o Estado.

Historicamente, os portos localizados em regiões estuarinas têm depositado os sedimentos dragados próximos às áreas de origem, sem qualquer monitoramento da qualidade e controle da dispersão destes em função da hidrodinâmica local. Isso porque até o ano de 2004 não existia uma legislação nacional específica para o licenciamento ambiental de dragagens.

O processo de licenciamento para o aprofundamento e manutenção de canal, berços e bacia de evolução dos TPPF configura uma das exceções nacionais na área de dragagem, em termos de monitoramento dessa atividade. Já que esse licenciamento foi conduzido por meio de parceria entre o Instituto Brasileiro de Meio Ambiente e Recursos Naturais Renováveis (Ibama) e o Centro de Estudos do Mar da Universidade Federal do Paraná (2001-2002), sendo esse último responsável pelo monitoramento.

\section{DRAGAGEM, CONTAMINANTES, ÁREAS DE DESPE- JO E A RESOLUÇÃO CONAMA 344}

Em função do monitoramento supramencionado, foi diagnosticada a existência de contaminantes nos materiais dragados, tais como metais pesados, arsênio, hidrocarbonetos, entre outros elementos considerados poluentes. Diante dessa realidade, pesquisadores do Centro de Estudos do Mar da UFPR enfatizaram a necessidade de estudar áreas de despejos apropriadas para esses sedimentos, ainda que na época inexistisse uma legislação brasileira para indicar o destino final, conforme a classificação nos níveis de contaminação. Contudo, esse pensamento não enfatizou, na mesma proporção, a necessidade de estudar a origem desses contaminantes.

Dos contaminantes a discussão se estendeu para a dispersão dos sedimentos dos materiais dragados, de modo a criticar as áreas de despejos, até então, licenciadas (no caso das dragagens para os TPPF, às margens ao longo do canal), ressaltando que tais materiais estavam retornando para o canal, com isso comprometendo a manutenção das áreas dragadas.

Nesse sentido, integrado com a questão do monitoramento das dragagens, salienta-se a necessidade de estudos de áreas de despejos apropriadas, seja em função do problema dos contaminantes como da dispersão dos sedimentos dragados. A referida discussão influenciou o conteúdo da primeira resolução para o licenciamento de dragagens do país, a Resolução Conama 344. A mesma entrou em vigor no ano de 2004 e determina o destino apropriado para os sedimentos dragados segundo os níveis de contaminação.

Entretanto, o conteúdo da Resolução não expressa nenhuma preocupação em apontar estudos para desenvolver ações mitigadoras dos impactos ambientais causados pelas dragagens, sendo que tais ações estão condicionadas a estudos sobre a origem do assoreamento e dos contaminantes. Essa discussão também não é priorizada na crítica acadêmica, uma vez que a metodologia utilizada para a construção do conhecimento estuda o fenômeno sem necessariamente investigar a sua origem numa perspectiva holística.

Em virtude dessa realidade, a questão dos licenciamentos das dragagens foi centralizada nos diagnósticos sobre os tipos de sedimentos e níveis de contaminantes existentes, sendo que estes passaram a determinar os critérios para áreas de despejos. Tais níveis não consideram o ambiente geoquímico local, formado por compartimentos geológicos e geomorfológi-cos distintos e interligados por uma densa rede hidrográ-fica.

A forma como a Resolução Conama 344 foi elaborada despeculiariza os estuários onde estão situados os portos brasileiros, transformando suas diferentes formações geoquímicas, com possíveis níveis naturais de metais pesados, em conceitos abstratos de níveis de contaminações. Dessa forma, interpreta-se que as bacias de drenagem associadas aos ambientes estuarinos podem estar transportando metais pesados por lixiviação, compondo um único cenário, no qual a presença de 
PAULA, E. V. de. et al. Controle do assoreamento e dos contaminantes...

contaminantes só pode ser de origem antrópica.

No caso das dragagens dos Terminais Portuários da Ponta do Félix, a existência de contaminantes diagnosticados nos sedimentos pelos monitoramentos (não há comprovação de que os metais pesados diagnosticados têm sua origem na poluição), alguns considerados acima dos níveis tolerados pela legislação (Resolução Conama 344/04), tornou a dragagem mais onerosa em função da distância de áreas de despejo licenciadas pelo Ibama para o depósito dos sedimentos. Conforme Figura 1, uma região de despejo situa-se na entrada do Estuário de Paranaguá, quais sejam: Área Circular Externa (ACE) e Banco dos Ciganos, cerca de
55 km de distância dos berços dos Terminais Portuários da Ponta do Félix.

\section{O PROGRAMA CAD: CONTAMINANTES, ASSOREA- MENTO E DRAGAGEM}

A ameaça de inviabilização das atividades portuárias, em função dos custos com dragagens de manutenção como o caso do Porto de Antonina, torna necessário investigar a origem do assoreamento e dos contaminantes, com vistas a desenvolver planos de ação que venham a atenuá-los e a viabilizar áreas de despe-

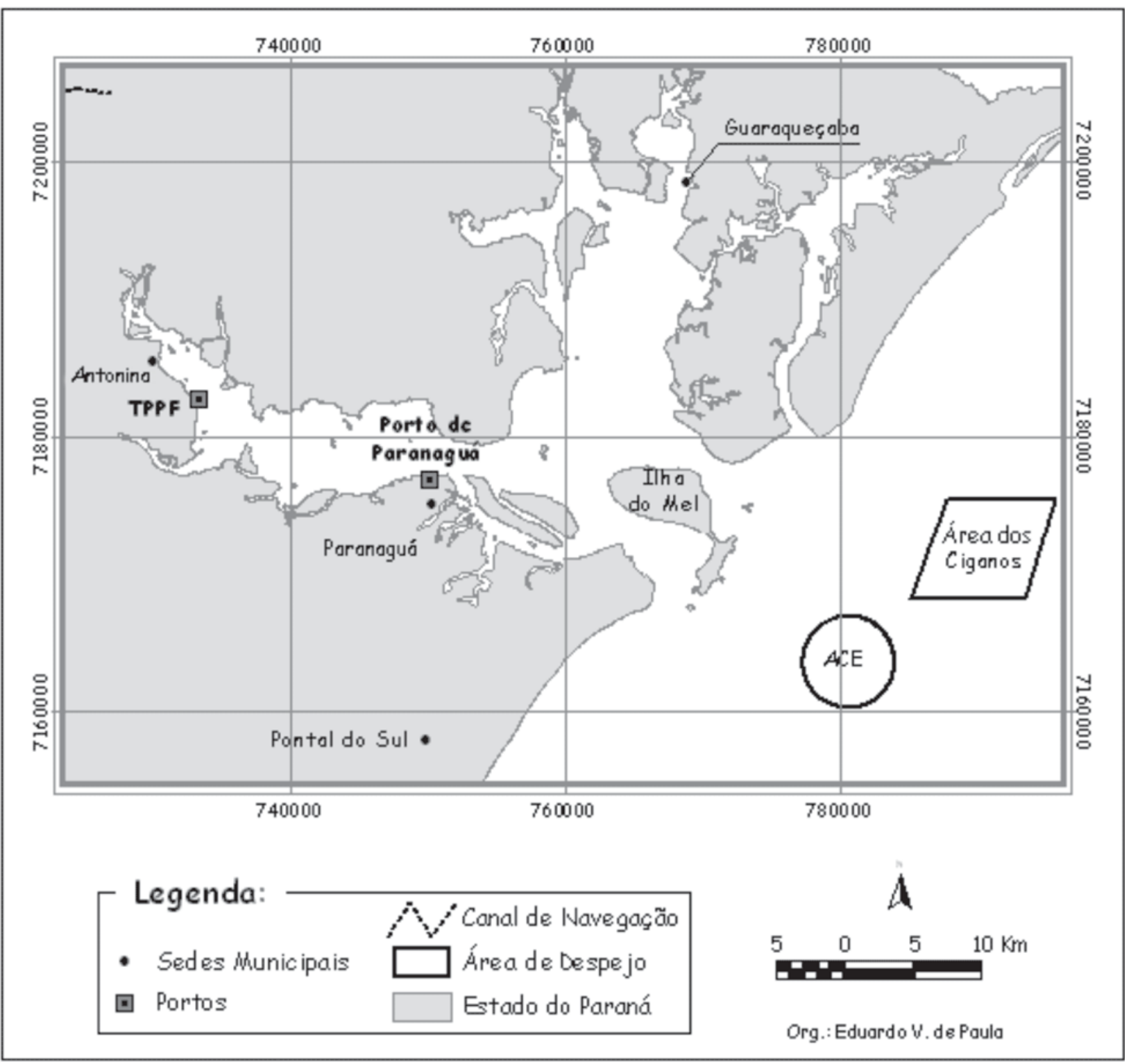

FIGURA 1 - ÁREAS LICENCIADAS PARA DESPEJOS DOS SEDIMENTOS DRAGADOS 
jo alternativas. Ou seja, despejos próximos às áreas de dragagem e atendendo à legislação de licenciamento ambiental correspondente.

Diante disso, atrelado aos programas do Sistema de Gestão Ambiental dos Terminais Portuários da Ponta do Félix, foi criado o Programa CAD - Contaminantes, Assoreamento e Dragagem - que tem por objetivos investigar a origem do assoreamento, dos contaminantes e simular, por meio de recursos de modelagem numérica, a dispersão dos sedimentos transportados pelas bacias de drenagem na hidrodinâmica da Baía de Antonina.

O Programa CAD está sendo desenvolvido pela Associação de Defesa do Meio Ambiente e do Desenvolvimento de Antonina (Ademadan) e conta com a parceria de instituições, como: o Instituto Tecnológico Simepar, o Centro de Estudos do Mar da UFPR e as Faculdades Integradas Espírita.

Os estudos elaborados têm sido imprescindíveis para organizar programas de gestão de bacias hidrográficas, a fim de atenuar o assoreamento e a emissão de contaminantes devido à ocupação e mudanças no uso da terra. Concomitante a esses objetivos, o programa prevê estudos de áreas alternativas de despejos para material dragado no interior da baía, por meio de ilhas artificiais destinadas à reprodução de manguezais. Os planos de ações compensatórias do assoreamento, dos contaminantes e das dragagens (inclui áreas de despejos), bem como o monitoramento dessas ações, fundamentam o planejamento das dragagens.

Nessa perspectiva, as renovações das licenças de dragagens relacionadas à manutenção dos portos brasileiros estariam condicionadas ao monitoramento das ações mitigadoras e compensatórias determinadas pelos licenciamentos. Porém, para viabilizar tal medida é preciso rever tanto o conteúdo quanto o método proposto na Resolução Conama 344, adotando novas abordagens, como as sugeridas pelo Programa CAD.

No referido programa, a necessidade de planejamento de dragagens para viabilizar o plano de expansão portuária do Estado do Paraná está sendo centrada em dois aspectos: desenvolver metodologias de gestão de bacias hidrográficas e monitorar a dispersão dos sedimentos e hidrodinâmica das Baías de Antonina e Paranaguá.

A metodologia utilizada integra equipes interdisciplinares subdivididas por área de conhecimento, como: equipe dos estudos sobre a origem dos contaminantes; equipe dos estudos da dispersão dos sedimentos e hidrodinâmica por meio de simulações por modelagem numérica; equipe dos estudos biológicos da biota aquática; e equipe dos estudos voltados à caracterização e gestão das bacias hidrográficas. Dessa forma, integrase pesquisa bibliográfica, documental e de campo com a utilização de ferramentas de geoprocessamento, sendo as equipes orientadas na perspectiva sistêmica.

Assim, torna-se viável desenvolver uma metodologia em que a construção do conhecimento integra a dinâmica dos ambientes costeiros com a dinâmica das bacias de drenagem da Serra do Mar, as quais interagem com a Baía de Antonina no contexto socioeconômico que historicamente vem se desenvolvendo na região. Este artigo contempla a delimitação da área de abrangência do Programa CAD, os objetivos, a metodologia e os resultados parciais alcançados pela equipe dos estudos das bacias de drenagem.

\section{DELIMITAÇÃO DA BAÍA DE ANTONINA E BACIAS DE DRENAGEM}

A área de abrangência da pesquisa inclui a Baía de Antonina e as respectivas bacias hidrográficas que drenam da Serra do Mar, conforme Figura 2. O trecho da Baía de Antonina considerado neste estudo apresenta cerca de $100 \mathrm{~km}^{2}$ (incluindo-se as ilhas), tendo a área de drenagem cerca de $1.621,5 \mathrm{~km}^{2}$, dividida em cinco bacias hidrográficas e quatro áreas incrementais que se encontram listadas na Tabela 1.

TABELA 1- BACIAS DE DRENAGEM E ÁREAS INCREMENTAIS DA BAÍA DE ANTONINA

\begin{tabular}{lll}
\hline Nome & Área $\mathbf{k m}^{\mathbf{2}}$ & Perímetro km \\
\hline Bacia Hidrográfica do Rio Nhundiaquara & 519,3 & 140,2 \\
Bacia Hidrográfica do Rio Cachoeira & 429,2 & 126,6 \\
Bacia Hidrográfica do Rio Sagrado & 137,7 & 71,8 \\
Bacia Hidrográfica do Rio Cacatu & 107,1 & 55,7 \\
Bacia Hidrográfica do Rio Faisqueira & 103,3 & 61,1 \\
Área Incremental 01 & 165,3 & 69,8 \\
Área Incremental 02 & 95,8 & 76,6 \\
Área Incremental 03 & 15,8 & 21,3 \\
Área Incremental 04 & 48,0 & 36,2 \\
\hline
\end{tabular}




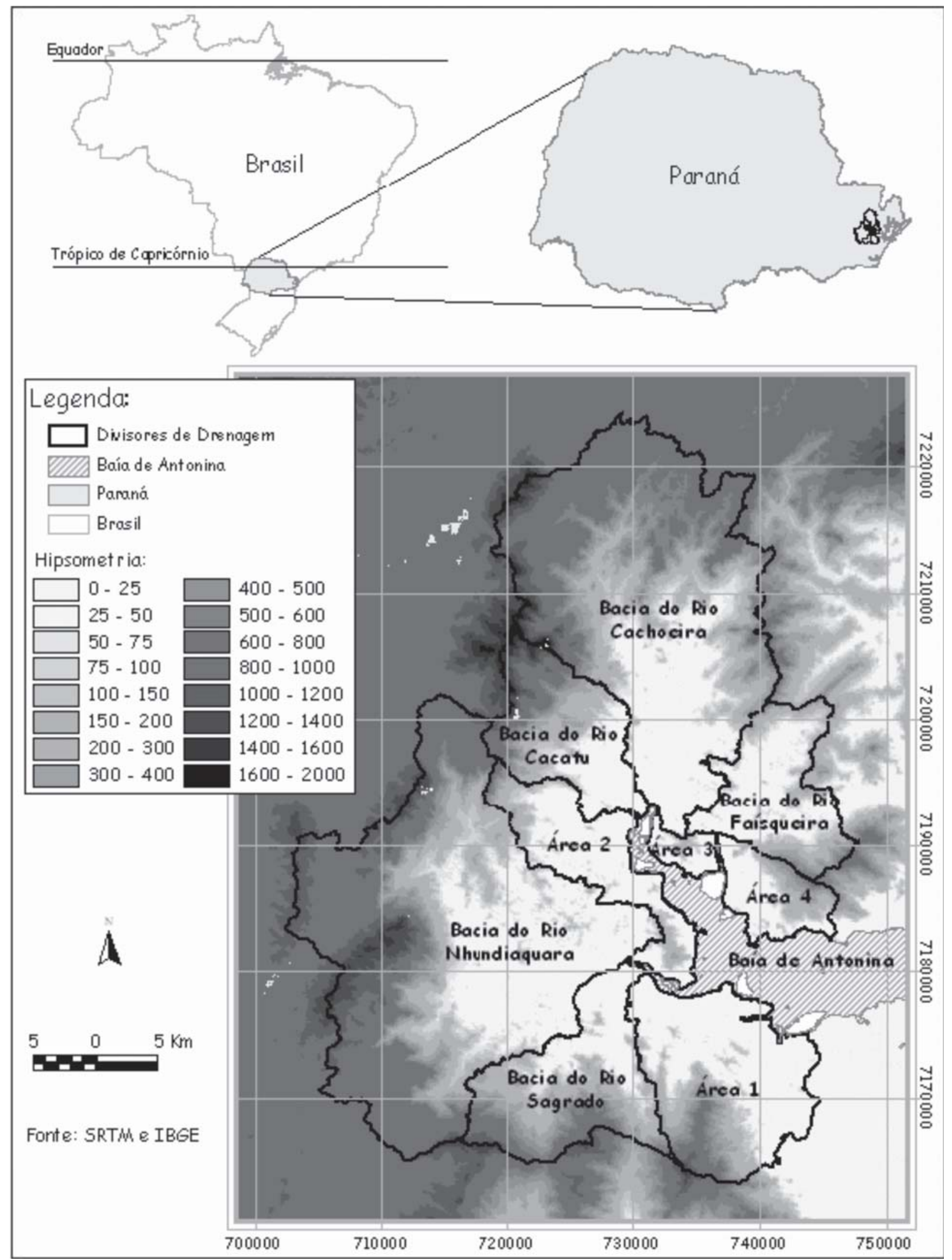

FIGURA 2 - LOCALIZAÇÃO DA ÁREA DE ESTUDO 
Compreendendo bacia hidrográfica como sendo "uma área que drena água, sedimentos, e materiais dissolvidos para uma saída comum, num determinado ponto de um canal fluvial" (NETTO, 1998, p. 97), foram delimitadas apenas as cinco maiores bacias internas à área de estudo. As bacias hidrográficas de menor dimensão foram agrupadas nas chamadas áreas incrementais, resultando num total de quatro áreas.

A delimitação das bacias de drenagens e áreas incrementais foi efetuada sobre cartas topográficas da Divisão de Serviços Geográficos do Exército (DSG), na escala 1:25.000, elaboradas no ano de 2002. É pertinente salientar que os limites políticos foram desconsi-derados, pois sua utilização não oferece suporte às análises ambientais, uma vez que esses limites, em muitos casos, não coincidem com os limites das bacias hidrográficas.

A relação das cartas utilizadas encontra-se em Paula e Cunico $(2005$, p. 3). Tais cartas foram obtidas em formato de extensão .PDF, junto à Secretaria de Estado do Meio Ambiente e Recursos Hídricos. Desses arquivos extraíram-se dados tanto no formato raster quanto no formato vetorial. Os dados raster foram georreferenciados e salvos em extensão .TIF, com o auxílio do software Envi. 3.4. As cartas em formato raster e georreferenciadas são denominadas ScanMaps, sobre estes delimitou-se as bacias em questão, considerando-se os seus divisores de drenagem, ou seja, a porção do relevo mais elevada altimetricamente.

Para a delimitação da Baía de Antonina, e das ilhas contidas nesta, também se fez uso das cartas topográficas da DSG, sendo que se considerou baía aqueles canais com até 150 metros de largura. Os canais com largura inferior a 150 metros foram classificados como parte da rede hidrográfica.

\section{A GESTÃO DAS BACIAS QUE DRENAM PARA A BAÍA DE ANTONINA}

A preocupação com a problemática ambiental e sua abordagem apresenta-se como uma constante não só na ciência geográfica como também nos demais campos do conhecimento. Nesse contexto, cabe aos estudiosos da temática ambiental delinear novas possibilidades de análise, integrando as subáreas do conhecimento e suas respectivas construções teórico-metodológicas a uma perspectiva conjuntiva, baseada na interdependência dos fenômenos físicos, biológicos, culturais e sociais, na tentativa de (re)formular e auxiliar na gestão ambiental.

A gestão ambiental pode ser compreendida, conforme Lanna (1995), como uma atividade voltada para a formulação de diretrizes, estruturação de sistemas gerenciais e tomadas de decisão, objetivando o uso, proteção, conservação e monitoramento dos recursos naturais e socioeconômicos de maneira coordenada, em um determinado recorte geográfico.

Salienta-se que o manejo inadequado, tanto em áreas urbanas como rurais, tem sido a principal causa da degradação ambiental, cujas conseqüências podem ser: a aceleração dos processos erosivos, desmatamentos, desertificação, poluição, inundações, entre outros. Acredita-se que ações coordenadas possam minimizar a ocorrência de impactos ambientais negativos decorrentes da ação antrópica indiscriminada.

A equipe responsável pelos estudos das bacias de drenagem tem dentre seus objetivos principais a caracterização geográfica da área que drena para a Baía de Antonina, visando a posterior geração das cartas de vulnerabilidade ambiental e construção de um banco de dados socioambiental georreferenciado. Com essas informações e envolvimento das partes interessadas pretender-se-á iniciar o monitoramento e o gerenciamento das bacias hidrográficas que escoam para o estuário com o intuito de mitigar o assoreamento e os contaminantes diagnosticados na Baía de Antonina.

\section{ASPECTOS FÍSICOS DA BAÍA DE ANTONINA E BA- CIAS DE DRENAGEM}

CLIMA

O estudo do tempo e do clima é de primordial importância e central no amplo campo da ciência ambiental. Os processos atmosféricos exercem influência, da mesma maneira que são influenciados, pelos processos que se desenvolvem na biosfera, hidrosfera e litosfera. Essa integralidade da paisagem pode ser mais bem compreendida a partir de uma abordagem sistêmica, a qual expressa o sentido de uma geografia física global (espaço geográfico), composto de dois subconjuntos: um físico (potencial ecológico e exploração biológica) e outro humano (BERTRAND, 1968).

O clima demonstra-se condicionado por fatores estáticos e por fatores dinâmicos. Os fatores estáticos correspondem à latitude, altitude, relevo e distância do oceano, enquanto que os fatores dinâmicos decorrem da movimentação dos sistemas atmosféricos, representados pelas massas de ar e frentes a elas associadas. Segundo Sorre (1984) o clima pode ser definido como "o ambiente atmosférico constituído pela série de estados da atmosfera acima de um lugar em sua sucessão habitual".

No litoral do Estado do Paraná são dois os sistemas atmosféricos predominantes que definem o clima no âmbito regional: Massa Polar Atlântica (MPA), origi- 
nária do Anticiclone Migratório Polar, e Massa Tropical Atlântica (MTA), originária no Anticiclone Semifixo do Atlântico. A Frente Polar Atlântica (FPA) é fundamental no controle do regime pluvial na região o ano todo, conforme identificou Monteiro (1968).

Para a região em questão, o clima é considerado do tipo Cfa, chuvoso tropical sempre úmido, de acordo com a classificação de Koeppen (IAPAR, 2000). Na zona litorânea, em conseqüência do rápido aquecimento do solo com o sol nascente, ocorrem brisas marítimas de leste e sudoeste, aproximadamente ao meio-dia, soprando continente adentro. Ao anoitecer, o solo esfria de forma mais rápida que o mar, ocorrendo inversão do gradiente de pressão de forma que o vento passa a soprar da terra em direção ao oceano. Apesar dessa alternância entre brisas marítimas e continentais, os ventos predominantes são os influenciados pelo alísio sudeste. $\mathrm{Na}$ planície a temperatura média é de $21,1^{\circ} \mathrm{C}$.

Sobre a Serra do Mar, a temperatura média anual registrada está entre $14^{\circ} \mathrm{C}$ até a mais baixa de $11,5^{\circ} \mathrm{C}$. Devido à expressão do seu relevo com bruscas variações altimétricas, a temperatura média sobre esse ambiente diminui cerca de $0,6^{\circ} \mathrm{C}$ a cada 100 metros de altura acima. A Serra do Mar constitui uma barreira natural para os ventos regulares que sopram do oceano proveniente de sudeste. A umidade desses ventos se condensa na vertente da Serra, formando uma camada de estratos entre 1000 e 1200 metros. Devido à concentração dessa umidade ocorre a chuva orográfica nas encostas a leste da Serra, onde são registrados os mais altos índices pluviométricos do Estado (MAACK,1968).

Para o estudo da pluviosidade, foram utilizadas 17 estações de medição, as quais encontram-se listadas na Tabela 2. Antes de qualquer análise dos dados de chuva, é importante apontar que a grande maioria das estações está locada sobre a planície, e outra parcela no início da encosta leste da Serra do Mar. Sendo assim, somente a estação que representa bem a vertente leste da Serra do Mar é a estação Véu da Noiva (atualmente desativada), cujo total pluviométrico anual médio para seu período de funcionamento foi de $3.639 \mathrm{~mm}$.

Para a obtenção dos mapas de precipitação pluviométrica se fez uso do método de interpolação Spline tencionado, implementado na extensão Spatial Analyst do software ArcView GIS 3.3. Esse método de interpolação utiliza uma expressão polinomial para ajustar uma superfície analítica que inclua todos os pontos amostrais. Maiores detalhes desse método são encontrados em Mitasova e Mitas (1993), Mitasova e Hofierka (1993), Mitas e Mitasova (1999).

TABELA 2 - ESTAÇÕES SELECIONADAS PARA A CARACTERIZAÇÃO DA PRECIPITAÇÃO NAS BACIAS DE DRENAGEM DA BAÍA DE ANTONINA

\begin{tabular}{r|l|r|r|r|l|l}
\hline Código & \multicolumn{1}{|c|}{ Estação } & Latitude & Longitude & Altitude & Período & Operador \\
\hline 83844 & Paranaguá & -25.5333 & -48.5166 & 4.5 & $1961-2005$ & INMET \\
\hline 2548000 & Morretes & -25.4667 & -48.8331 & 8.0 & $1939-2005$ & ANA \\
\hline 2548002 & Véu de Noiva & -25.4331 & -48.9500 & 680.0 & $1940-1996$ & Aneel \\
\hline 2548003 & Colônia Cachoeira & -25.2331 & -48.7500 & 80.0 & $1946-2005$ & Aneel \\
\hline 2548018 & Bairro Alto & -25.2331 & -48.7331 & 400.0 & $1951-1982$ & SUDERHSA \\
\hline 2548025 & Limoeiro & -25.3167 & -48.7000 & 8.0 & $1939-1952$ & ANEEL \\
\hline 2548027 & Marumbi & -25.5058 & -48.8742 & 60.0 & $1948-2005$ & SUDERHSA \\
\hline 2548036 & Posto Fiscal km 309 & -25.0833 & -48.6000 & 702.0 & $1974-1994$ & SUDERHSA \\
\hline 2548038 & Morretes & -25.5000 & -48.8170 & 59.0 & $1966-2005$ & Iapar \\
\hline 2548044 & Passo do Vau & -25.5364 & -48.8467 & 73.0 & $1974-2005$ & ANA \\
\hline 2548046 & Fazenda Bom Jesus & -25.3331 & -48.6000 & 216.0 & $1974-2001$ & SUDERHSA \\
\hline 2548047 & São João da Graciosa & -25.3831 & -48.8667 & 159.0 & $1974-2005$ & SUDERHSA \\
\hline 2548049 & Colônia Santa Cruz & -25.6167 & -48.6000 & 79.0 & $1974-1994$ & SUDERHSA \\
\hline 2548051 & Cubatão & -25.8167 & -48.7500 & 12.0 & $1974-1997$ & SUDERHSA \\
\hline 2548052 & Ilha do Rio Claro & -25.8128 & -48.9236 & 237.0 & $1974-2005$ & SUDERHSA \\
\hline 2548068 & Antonina & -25.4331 & -48.7667 & 74.0 & $1974-2005$ & SUDERHSA \\
\hline 2548070 & Antonina & -25.2170 & -48.8000 & 60.0 & $1977-2005$ & lapar \\
\hline
\end{tabular}


A única região do Estado do Paraná cujo total pluviométrico anual é superior aos $2.000 \mathrm{~mm}$ é a porção litorânea e vertente leste da Serra do Mar (Figura 3), "onde é maior a freqüência da frente polar, e o relevo de escarpas abruptas faz aumentar a precipitação" (NIMER, 1989 p. 212). Quanto à sazonalidade das chuvas, podese afirmar que estas ocorrem ao longo de todo o ano, embora se perceba uma maior abundância da pluviosidade no verão (Figura 4), enquanto que os meses menos chuvosos sejam de inverno e secundariamente de outono. Essa maior quantidade de chuvas no trimestre mais quente (dezembro, janeiro e fevereiro), deve ser atribuída à conjugação de dois fatores dinâmicos:

maior freqüência de frente polar motivada pela maior freqüência de semi-estacionamento sobre o Paraná, nesta época, e pelas ocorrências de chuvas de con- vergência trazidas pelas correntes perturbadas de oeste, representadas pelas linhas de IT (chuvas de verão) tão comuns nesta época do ano (NIMER, 1989, p. 217).

Quanto ao problema do assoreamento e dos contaminantes na Baía de Antonina, o clima denota considerável influência, visto que os elevados índices pluviométricos associados a temperaturas altas favorecem tanto os processos de intemperismo, e por conseqüência formando solos espessos, quanto os processos de lixiviação, extraindo elementos (tais como metais pesados ${ }^{4}$ ) das rochas e do solo. Nos meses de verão, devido principalmente às chuvas convectivas, temse o escoamento superficial ampliado e nas áreas com ausência de cobertura vegetal o transporte de sedimentos para a rede de drenagem é expressivo.

FIGURA 3 - PRECIPITAÇÃO PLUVIOMÉTRICA MÉDIA ANUAL NAS BACIAS DE DRENAGEM DA BAÍA DE ANTONINA (MÉDIA HISTÓRICA - 1973-2002)

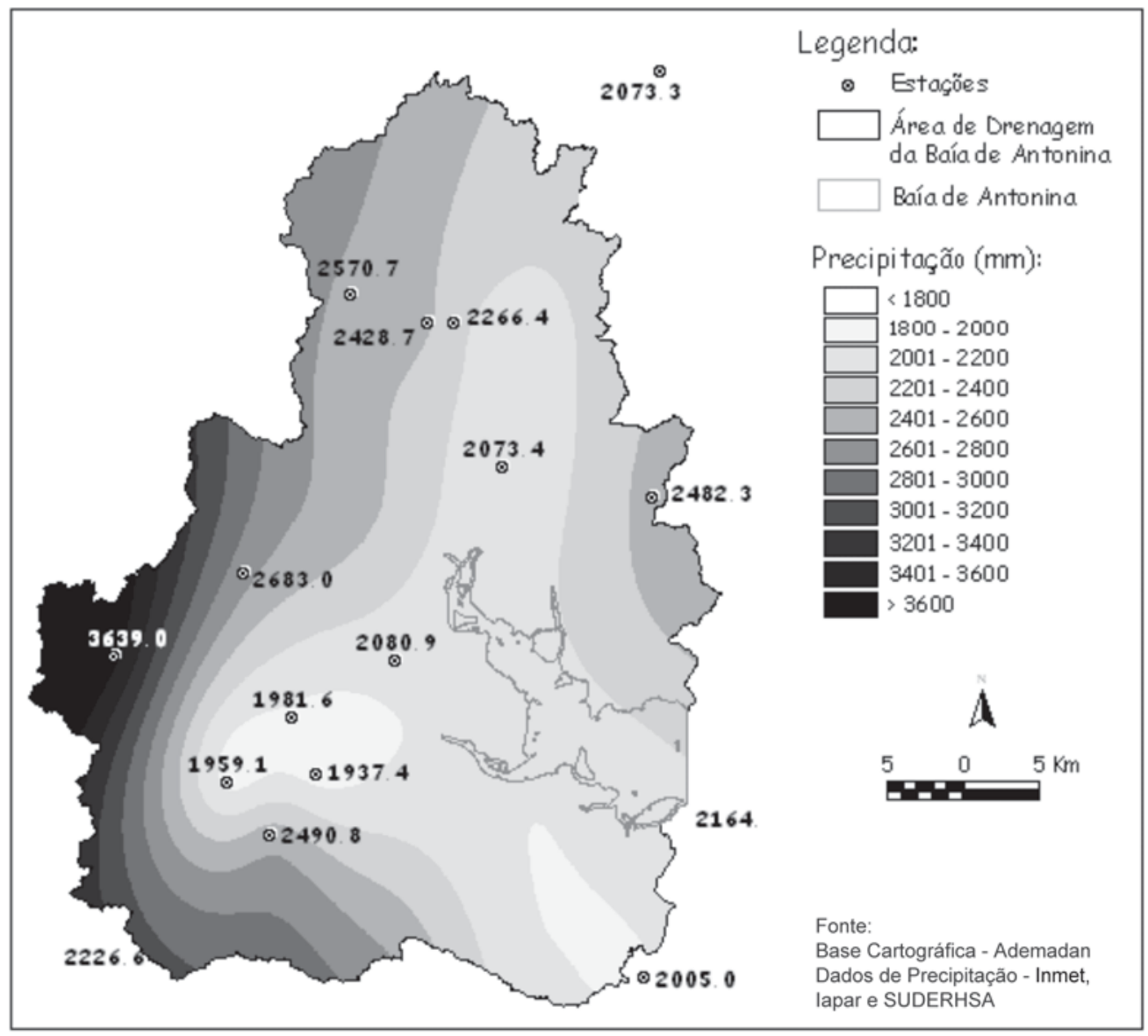

${ }^{4}$ Rebelo et al. (2005) ao analisar o quadro geológico-geográfico e geoquímico da região da Baía de Antonina (PR), objetivando diagnosticar a origem mais provável das concentrações de metais pesados e arsênio ( $\mathrm{Cd}, \mathrm{Pb}, \mathrm{Cu}, \mathrm{Cr}, \mathrm{Ni}, \mathrm{Zn}, \mathrm{Hg}$ e As) existentes nos sedimentos argilosos e carbonosos daquela unidade fisiográfica, verificaram que a origem principal mais provável dos elementos químicos discutidos são ocorrências diferenciadas de rochas e minerais e seus produtos de alteração, existentes na região de Morretes - Antonina. 


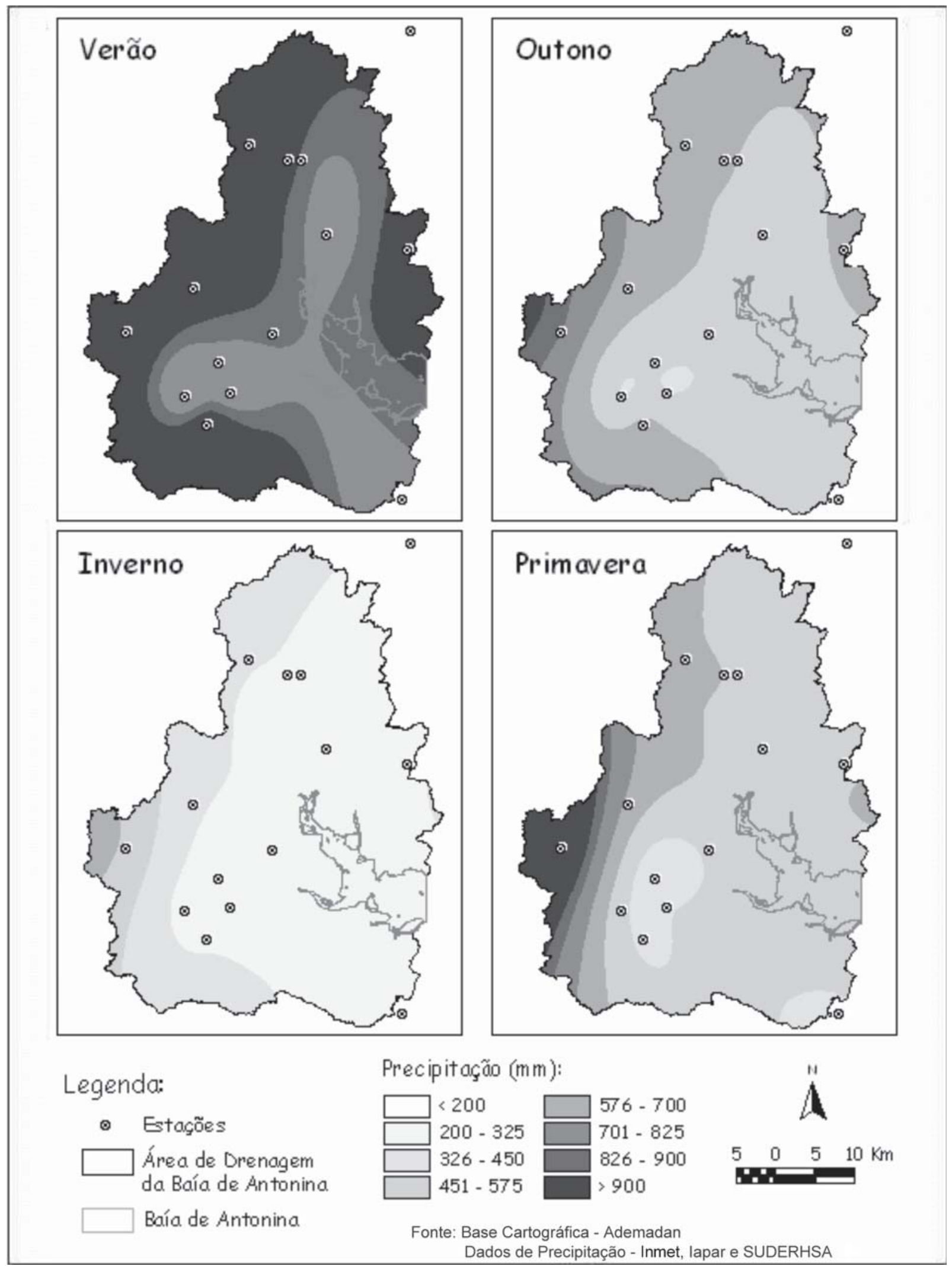

FIGURA 4 - PRECIPITAÇÃO PLUVIOMÉTRICA MÉDIA SAZONAL NAS BACIAS DE DRENAGEM DA BAÍA DE ANTONINA (MÉDIA HISTÓRICA 1973-2002) 
PAULA, E. V. de. et al. Controle do assoreamento e dos contaminantes...

\section{GEOLOGIA}

A geologia da área de drenagem da Baía de Antonina é bastante complexa, abrangendo desde ro- chas de idade proterozóica até sedimentos recentes da Planície Costeira do litoral do Paraná.

As rochas de alto grau de metamorfismo configuram, sem dúvida, as litologias mais importantes e de

TABELA 3 - CLASSES DE GEOLOGIA NA ÁREA DE DRENAGEM DA BAÍA DE ANTONINA

\begin{tabular}{|c|c|c|}
\hline Código & Unidade Geológica & Area $\left(\mathrm{km}^{2}\right)$ \\
\hline QAr & Sedimentos recentes & 0,05 \\
\hline QHa & Sedimentos recentes & 204,11 \\
\hline QHa1 & Sedimentos recentes & 8,45 \\
\hline QHa2 & Sedimentos recentes & 13,15 \\
\hline QHmg & Sedimentos recentes & 72,47 \\
\hline QHmo & Sedimentos recentes & 48,63 \\
\hline Qm & Sedimentos recentes & 10,80 \\
\hline QHc & Sedimentos recentes & 129,72 \\
\hline QHcs & Sedimentos recentes & 19,90 \\
\hline Qt & Sedimentos recentes & 27,26 \\
\hline $\mathrm{Ta}$ & Formação Alexandra & 7,68 \\
\hline Ta1 & Formação Alexandra & 1,33 \\
\hline JKdp & Intrusivas Básicas & 1,41 \\
\hline Egm & Intrusivas Granitóides & 0,14 \\
\hline Egg & Formação Guaratubinha & 0,16 \\
\hline Ega & Formação Guaratubinha & 0,69 \\
\hline Egs & Formação Guaratubinha & 2,58 \\
\hline PEg1 & Suite álcali-granitos & 16,74 \\
\hline PEg2 & Suite álcali-granitos & 207,04 \\
\hline PEg4 & Suite álcali-granitos & 19,23 \\
\hline PEg6 & Suite álcali-granitos & 60,58 \\
\hline PEg7 & Suite álcali-granitos & 11,43 \\
\hline APImgi & CGM - Complexo Gnáissico-Migmatítico & 0,13 \\
\hline APImge & CGM - Complexo Gnáissico-Migmatítico & 287,65 \\
\hline APImgm & CGM - Complexo Gnáissico-Migmatítico & 170,15 \\
\hline APImga & CGM - Complexo Gnáissico-Migmatítico & 26,48 \\
\hline APImgr & CGM - Complexo Gnáissico-Migmatítico & 74,65 \\
\hline APlsgf & CGM - Complexo Gnáissico-Migmatítico & 71,14 \\
\hline APlg3 & CGG - Complexo Granítico-Gnáissico & 1,69 \\
\hline APlg7 & CGG - Complexo Granítico-Gnáissico & 1,72 \\
\hline APIg8 & CGG - Complexo Granítico-Gnáissico & 4,81 \\
\hline APIrmx & Complexo Metamórfico sem denominação & 13,31 \\
\hline APIcmq & Complexo Cachoeira & 0,67 \\
\hline APIcca & Complexo Cachoeira & 2,91 \\
\hline APIcq & Complexo Cachoeira & 10,70 \\
\hline APlcga & Complexo Cachoeira & 2,26 \\
\hline APIcgm & Complexo Cachoeira & 0,88 \\
\hline APIcxm & Complexo Cachoeira & 82,22 \\
\hline APIsn & Complexo Serra Negra & 12,94 \\
\hline
\end{tabular}


ampla distribuição na área. Com relação a essas rochas, as mais comuns e de maior ocorrência são os migmatitos e gnaisses cuja interdependência é bastante estreita e, freqüentemente, de duvidosa separação no campo (SALAMUNI; ROCHA, 2002). Ocorrem também rochas graníticas componentes de consideráveis extensões da Serra do Mar cujos exemplos mais expressivos são as Serras do Marumbi, do Leão, Serra da Igreja, bem como do Anhangava, entre outros.

Já na planície litorânea, misturam-se sedimentos de origem marinha, como cordões arenosos, com sedimentos aluviais síltico-arenosos e argilosos fluviais que progridam ou avancem por sobre os sedimentos de fundo e sobre manguezais. Essa região apresenta morfologia profundamente recortada pelos complexos estuarinos, os quais originam um extenso litoral de costas protegidas, caracterizado pela existência de planícies de maré, cobertas principalmente por vegetação de mangue, sendo que em alguns locais ocorrem costões rochosos e pequenas praias (PARANÁ, 2003, p. 12).

Tomando-se por referência os dados representados na Tabela 3, gerada a partir da carta geológica, notase a existência de 39 classes geológicas na área de drenagem da Baía de Antonina. Dentre as quais, destacam-se: Complexo Gnáissico-Migmatítico (APImge) com $16,7 \%$ da área total, Granito Serra Graciosa com $13,3 \%$, Sedimentos Recentes (QHa) 12,1\%, Sedimentos Recentes (QHc) $11,6 \%$ e Complexo GnáissicoMigmatítico (APImgm) 9,9\%.

Informações em maior nível de detalhe sobre as grandes unidades geológicas, associações litológicas, feições tectônicas e estruturais, bem como dos recursos minerais da região, podem ser encontradas em Paraná (2003, p. 20-56).

\section{PEDOLOGIA}

$\mathrm{Na}$ área de drenagem da Baía de Antonina, foram identificadas cinco classes de solos, conforme a mais recente classificação da Embrapa (1999). De acordo com a Tabela 4, verifica-se predomínio de solos do tipo Cambissolo (42,5\%), seguido do Argissolo VermeIho-Amarelo (17,3\%), Neossolo Litólico $(15,0 \%)$, Latossolo Vermelho-Amarelo $(14,6 \%)$ e Neossolo Quartzênico (10,6\%). É pertinente salientar que a escala do mapeamento de solos utilizada para este trabalho foi de 1:600.000, ou seja, muito reduzida para o propósito desta pesquisa. Dessa forma, tem-se apenas uma compreensão superficial da pedologia da área estudada.

\section{GEOMORFOLOGIA}

Pode-se identificar na área de abrangência do Programa CAD duas unidades geomorfológicas, sendo que cada uma comparece com seus limites perfeitamente identificáveis, não só pelas características morfológicas, como também pela topografia que as domina. Tais unidades são: o Litoral ou Planície Litorânea e a Serra do Mar (MAACK, 1968).

O Litoral é constituído por uma estreita faixa montanhosa afundada por falhamentos que originam a Serra do Mar. É um litoral de imersão, onde antigos vales e enseadas foram preenchidos por sedimentação marinha e terrestre. O relevo é muito suave, com pequenas ondulações e altitudes que somam alguns metros acima do nível do mar. São comuns os morros isolados e espigões que se destacam na topografia ou formando pequenos maciços na planície sedimentar. (PARANÁ, 2003, p. 10).

Segundo Cordani e Girandi (1967), a Serra do Mar é uma serra marginal de borda de planalto, com um desnível acentuadamente maior para o lado do oceano do que para o lado continental, mas possuindo taludes e vertentes abruptas nos dois flancos. O relevo no domínio dessa unidade é bastante acidentado, com vales profundos, estreitos e vertentes rochosas muito íngremes. Os cursos d'água principais estão encaixados em linhas de falha e de fraturas, conferindo à drenagem subseqüente um padrão retangular, às vezes, angular. Os blocos graníticos formam espigões alongados, salientes à topografia, orientados principalmente na direção NE-SW, exibindo um fraturamento característico. As partes mais baixas da Serra do Mar são ocupadas por

TABELA 4 - CLASSES DE SOLOS NA ÁREA DE DRENAGEM DA BAÍA DE ANTONINA

\begin{tabular}{l|r}
\hline \multicolumn{1}{c|}{ Tipo de Solo } & \multicolumn{1}{c}{ Área $\mathbf{( k m}^{\mathbf{2}} \mathbf{)}$} \\
\hline Cambissolo & 688,47 \\
\hline Argissolo Vermelho-Amarelo & 280,41 \\
\hline Neossolo Litólico & 243,05 \\
\hline Latossolo Vermelho-Amarelo & 237,30 \\
\hline Neossolo Quartzênicos & 172,32 \\
\hline
\end{tabular}


rochas gnáissicas-migmatíticas na forma de morros subarrendondados, muito recortados e com uma drenagem pouco subordinada às linhas tectônicas.

Para Oka-Fiori e Canali (1987), a zona da serra que acompanha a escarpa de falha do Complexo Cristalino é repartida por falhas transversais em blocos elevados e rebaixados. Em certos pontos, forma serras isoladas que têm denominações locais, as quais se elevam consideravelmente sobre o nível geral do interior. Oka-Fiori et al (2002) alegam que a Serra do Mar exerce um importante papel na geomorfologia paranaense, uma vez que constitui o divisor de águas que separa a região litorânea dos planaltos, cujas elevações se aproximam de 2000 metros de altura.

Metodologicamente, para a execução do presente trabalho, os dados de curvas de nível, pontos cotados e rede hidrográfica foram trabalhados e editados separadamente. As informações vetoriais, essenciais para confecção das cartas de hipsometria e declividade, foram extraídas das cartas topográficas anteriormente citadas, no entanto, as mesmas não apresentavam atributos. Diante disso, inseriu-se manualmente nas curvas de nível e pontos cotados as cotas altimétricas.

\section{Hipsometria}

A identificação e análise da hipsometria de uma bacia hidrográfica possibilita a observação altimétrica do relevo da área, fator importante na análise de processos relativos à dinâmica de uso e ocupação do solo e da formação de microambientes da mesma, dentre outros (MENDONÇA, 1999).

A distribuição das classes de altitudes de um mapa hipsométrico varia de acordo com a amplitude altimétrica (ponto mais elevado e menos elevado da bacia). A variação de cores buscou refletir a noção de incremento de relevo: verde para as áreas mais baixas, passando para o amarelo, laranja e marrom, à medida que a altitude se mostra mais expressiva.

\section{Declividade}

A análise da declividade permite evidenciar a distribuição das inclinações das superfícies do relevo, sendo essa característica relevante quando se analisa o uso e ocupação do solo de uma área, bem como o fluxo torrencial de superfície e os conseqüentes processos erosivos e arrastamento de materiais para o curso hídrico da bacia (MENDONÇA, Op. Cit.).

Quanto maior a inclinação das vertentes de determinada área, mais facilmente os processos erosivos se desenvolverão. A ausência de cobertura vegetal também contribuirá, nesse caso, para a aceleração destes processos, além de contribuir para as perdas agrícolas e a ocorrência de deslizamentos de terreno. A ocupação humana e as práticas agrícolas são fatores que estão diretamente condicionados pela inclinação das vertentes, ou seja, tais atividades desenvolvem-se com maior intensidade quanto mais plano for o terreno (MENDONÇA, 1999).

Uma carta de classes de declividade viabiliza, então, a observação de quais áreas seriam menos danosas à ocupação, restringindo usos. As classes estabelecidas para a confecção do mapa de declividade procuraram refletir a intensidade da declividade do terreno, sendo definidas a partir do trabalho proposto por De Biase (1995). Tal proposta revelou-se como a mais adequada, pois valoriza as variações da morfologia da área estudada.

\section{COBERTURA E USO DO SOLO}

A cobertura vegetal, bem como as áreas antropizadas (agropecuária e cidades) podem ser visualizadas a partir de imagens de média resolução, obtidas de sensores a bordo de satélites orbitais, tal como o LANDSAT ETM. Fazendo-se uso das diferentes bandas das imagens de satélite é possível distinguir as diferentes classes de vegetação, por meio de métodos de classificação digital, a exemplo do trabalho desenvolvido pelo Paraná (2002).

Dentre os diversos sistemas de classificação da vegetação, a nomenclatura mais utilizada atualmente por pesquisadores da área ambiental no Brasil é a desenvolvida pelo IBGE, na versão de 1992 do Manual de Classificação da Vegetação Brasileira. Esse sistema classifica a vegetação em formações e subformações com base na sua fisionomia, ou seja, no seu aspecto externo e em suas características parentes comuns.

As classes de cobertura do solo presentes na caracterização da área de drenagem da Baía de Antonina encontram-se descritas na Tabela 5, sendo estas extraídas do Paraná (2002). Observando-se essa tabela notase predomínio da Floresta Ombrófila Densa Submontana, cuja área corresponde a $26,5 \%$ da área total; seguida das classes de vegetação secundária: Fase Intermediária da Sucessão $(25,9 \%)$ e Fase Inicial da Sucessão (16,3\%); representando $15 \%$ da área total está a Floresta Ombrófila Densa Montana; atividades agropecuárias somam $3,9 \%$, enquanto que as demais classes abrangem menos de $3 \%$ do total, cada uma delas. 
PAULA, E. V. de. et al. Controle do assoreamento e dos contaminantes...

TABELA 5 - CLASSES DE COBERTURA DO SOLO NA ÁREA DE DRENAGEM DA BAÍA DE ANTONINA

\begin{tabular}{l|r}
\hline Classe & Area $\mathbf{k m}^{2}$ \\
\hline Floresta Ombrófila Densa das Terras Baixas - solos hidromórficos & 25,99 \\
\hline $\begin{array}{l}\text { Floresta Ombrófila Densa das Terras Baixas - solos semi- } \\
\text { hidromórficos e não hidromórficos }\end{array}$ & 16,55 \\
\hline Floresta Ombrófila Densa Submontana & 431,05 \\
\hline Floresta Ombrófila Densa Montana & 243,30 \\
\hline Floresta Ombrófila Densa Altomontana & 27,74 \\
\hline Floresta Ombrófila Densa Aluvial & 20,02 \\
\hline Floresta Ombrófila Mista Montana & 23,74 \\
\hline Refúgios Montanos e Altomontanos & 7,53 \\
\hline Formações Pioneiras com Influência Marinha - arbórea & 1,77 \\
\hline Formações Pioneiras com Influência Marinha - herbácea/arbustiva & 0,02 \\
\hline Formações Pioneiras com Influência Fluviomarinha - arbórea & 39,99 \\
\hline Formações Pioneiras com Influência Fluviomarinha - herbácea/ & 15,59 \\
\hline arbustiva & 4,32 \\
\hline Formações Pioneiras com Influência Fluvial - arbórea & 9,59 \\
\hline Formações Pioneiras com Influência Fluvial - herbácea/arbustiva & 264,67 \\
\hline Fase Inicial da Sucessão & 421,11 \\
\hline Fase Intermediária da Sucessão & 63,09 \\
\hline Agricultura, Pecuária e Outros & 5,25 \\
\hline Áreas Urbanas & 2,47 \\
\hline Reflorestamento &
\end{tabular}

\section{ÁREAS PRIORITÁRIAS PARA A RECUPERAÇÃO DA MATA CILIAR}

Para identificação das principais regiões originárias dos sedimentos que são carregados para os cursos hidrográficos e posteriormente para a Baía de Antonina, selecionaram-se as áreas teoricamente mais suscetíveis à erosão, seguindo a seguinte hierarquia: (1) argissolos, devido ao fato desses solos apresentarem-se como incoesos; (2) aluviões, essa classe foi extraída da carta geológica, estando relacionados a solos do tipo hidromórficos formados, sobretudo, por sedimentos recentes, os quais no período de cheias comumente são carreados para os cursos hidrográficos; (3) latossolos, em virtude destes apresentarem perfis verticais muito espessos.

Uma vez definidas as classes prioritárias selecionaram-se as áreas de uso agrícola e pecuário $(63,9$ km²), bem como os $5,3 \mathrm{~km}^{2}$ de área urbana e efetuou-se o cruzamento dessas áreas antropizadas com o mapa de áreas prioritárias. A partir desse cruzamento selecionaram-se apenas as regiões onde deveria existir mata ciliar, considerando-se como área de mata ciliar 100 metros a partir das margens dos rios que compõem a rede hidrográfica das bacias que drenam para a Baía de Antonina.

Dentre os resultados apresentados na Tabela 6 e na Figura 5, deve-se destacar a Bacia do Rio Nhundiaquara, Bacia do Rio Sagrado e Bacia do Rio Cachoeira, em virtude destas apresentarem expressivas áreas de uso humano sobre aluviões nas margens dos rios, que em geral são suscetíveis à erosão. Atenção especial deve ser dada também para a Área Incremental 02, por apresentar mais de $1 \mathrm{~km}^{2}$ antropizados, em regiões próximas aos cursos hidrográficos e sobre argissolos que são muito suscetíveis à erosão. 
PAULA, E. V. de. et al. Controle do assoreamento e dos contaminantes...

TABELA 6 - ÁREAS PRIORITÁRIAS DE CONTRIBUIÇÃO PARA O ASSOREAMENTO DA BAÍA DE ANTONINA

\begin{tabular}{l|l|r}
\hline \multicolumn{1}{c|}{ Nome } & Classe Prioritária & Área $\mathbf{( k m}^{\mathbf{2}} \mathbf{\text { }}$ \\
\hline \multirow{2}{*}{ Bacia Hidrográfica do Rio Cacatu } & (2) Aluviões & 0,36 \\
\cline { 2 - 3 } & (3) Latossolos & 0,08 \\
\hline \multirow{3}{*}{ Bacia Hidrográfica do Rio Cachoeira } & (1) Argissolos & 0,47 \\
\cline { 2 - 3 } & (2) Aluviões & $\mathbf{2 , 3 9}$ \\
\cline { 2 - 3 } & (3) Latossolos & $\mathbf{1 , 7 6}$ \\
\hline \multirow{2}{*}{ Bacia Hidrográfica do Rio Faisqueira } & (1) Argissolos & 0,51 \\
\cline { 2 - 3 } & (2) Aluviões & 0,37 \\
\hline \multirow{2}{*}{ Bacia Hidrográfica do Rio Nhundiaquara } & (1) Argissolos & 0,72 \\
\cline { 2 - 3 } & (2) Aluviões & $\mathbf{5 , 6 3}$ \\
\hline \multirow{2}{*}{ Bacia Hidrográfica do Rio Sagrado } & (2) Aluviões & $\mathbf{3 . 5 9}$ \\
\cline { 2 - 3 } & (3) Latossolos & 0.54 \\
\hline \multirow{2}{*}{ Área Incremental 01 } & (1) Argissolo & 0.78 \\
\cline { 2 - 3 } & (2) Aluviões & $\mathbf{1 , 3 6}$ \\
\hline \multirow{2}{*}{ Área Incremental 02 } & (1) Argissolos & $\mathbf{1 , 0 7}$ \\
\cline { 2 - 3 } & (2) Aluviões & 0,23 \\
\hline & & \\
\hline
\end{tabular}

\section{CONSIDERAÇÕES FINAIS}

O Programa CAD vem permitindo uma excelente caracterização das bacias de drenagem da Baía de Antonina, a partir de pesquisas bibliográficas de trabaIhos anteriormente desenvolvidos nessa área e, sobretudo, a partir da organização de um Banco de Dados Geográfico de extrema qualidade e disponível, em nível de detalhe, como para poucas regiões no território nacional.

É cabível ressaltar que a metodologia adotada para a definição das áreas prioritárias à recuperação da mata ciliar, fundamentada em conceitos geológicos e pedológicos, configurou uma tentativa introdutória do uso de ferramentas SIG, para a definição de cenários. Existem outras metodologias nas quais são considerados em maior nível de detalhamento o uso do solo, a cobertura pedológica, a geologia e a hidrografia, bem como a precipitação pluviométrica, a declividade do terreno, dados morfométricos, dados socioeconômicos, etc.
Diante do que foi apresentado, observa-se que o objetivo principal no início do projeto evolui do diagnóstico das áreas prioritárias, visando à recuperação da mata ciliar com o intuito de reduzir o assoreamento na Baía de Antonina, para um programa de gestão das bacias hidrográficas, o qual não se limita somente à recuperação da mata ciliar, mas considera o monitoramento do uso da terra frente às fragilidades e potencialidades do ambiente natural.

Para a seqüência do Programa CAD, além da base de dados físico-naturais e relativos à infra-estrutura das bacias hidrográficas internas à área de abordagem que já se encontra consolidada, também está sendo elaborado, a partir de aplicação de questionários e por amostragem, o cadastro das propriedades rurais e urbanas próximas à orla de Antonina. Cartas de Vulnerabilidade Ambiental estão sendo confeccionadas e uma metodologia para a gestão das bacias hidrográficas, com o auxílio de recursos de geoprocessamento, está sendo desenvolvida. 
PAULA, E. V. de. et al. Controle do assoreamento e dos contaminantes...

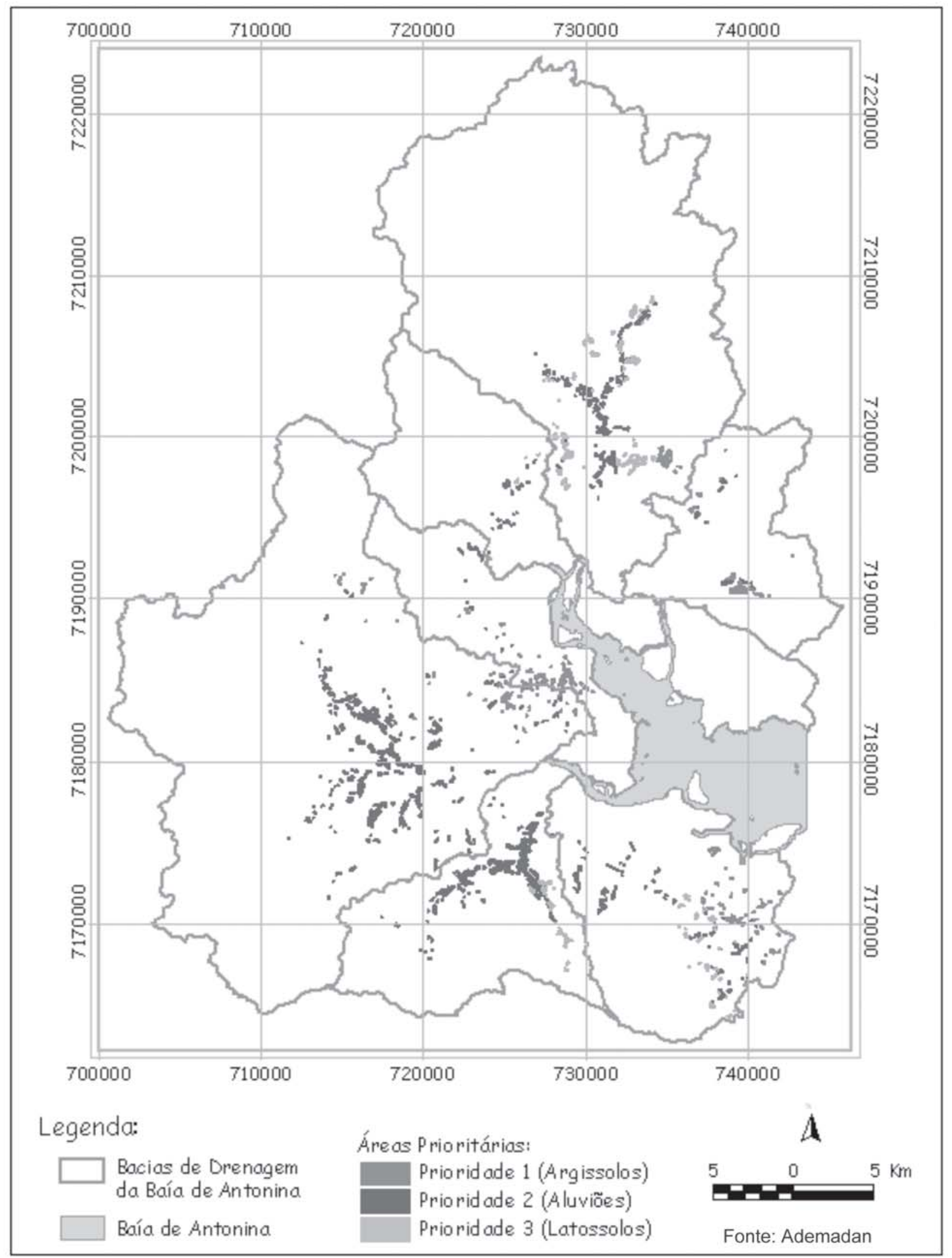

FIGURA 5 - ÁREAS PRIORITÁRIAS DE CONTRIBUIÇÃO PARA O ASSOREAMENTO DA BAÍA DE ANTONINA 


\section{REFERÊNCIAS}

BERTRAND. G. Paysage et Géographie Physique Globales: esquisse méthodologique. Toulouse: RGPSO, 1968.

CORDANI, U. G.; GIRARDI, V. A. V. Geologia da folha de Morretes - Departamento de Geologia, UFPR. Curitiba, 1967.

DE BIASE, M. A carta clinográfica: os métodos de representação e sua confecção. In: Revista do Departamento de Geografia. v. 6. São Paulo: FFLCH/ USP, 1995.

EMBRAPA. Sistema brasileiro de classificação de solos. Brasília: Embrapa/ Produção de Informação; Rio de Janeiro: Embrapa Solos, 1999.

IAPA. Cartas climáticas do estado do Paraná. Londrina, 2000.

LANNA, A. E. L. Gerenciamento de bacias hidrográficas. Aspectos conceituais e metodológicos. Brasília: Ibama, 1995.

MAACK, R. Geografia física do estado do Paraná. 3. ed. Curitiba: Imprensa Oficial, 2002.

MENDONÇA, F. A. Diagnóstico e análise ambiental de microbacia hidrográfica: proposição metodológica na perspectiva do zoneamento, planejamento e gestão ambiental. In: RA'E GA, Curitiba, n. 3, p. 67-89, 1999.

MITAS, L.; MITASOVA, H. Spatial interpolation. In: LONGLEY, M. F.; GOODCHILD, D. J.; MAGUIRE, D. W. (Ed.). Geographical information systems: principles, techniques, management and applications. Wilwy, 1999.

MITASOVA, H.; HOFIERKA, J. Interpolation by regularized spline with tension: II. Aplication to terrain modeling and surface geometry analysis. Mathematical Geology, v. 25, p. 657-669, 1993.

MITASOVA, H.; MITAS, L. Interpolation by regularized spline with tension: I. Theory and implementation. Mathematical Geology, v. 25, n. 6, p. 641-655, 1993.

MONTEIRO, C. A. F. Clima. Rio de Janeiro: IBGE, 1968. p. 14-166. (A grande Região Sul, tomo 1, v. 4).
NETTO, A. L. C. Hidrologia de encosta na interface com a geomorfologia. In: GUERRA, A. J. T.; CUNHA, S. B. Geomorfologia: uma atualização de bases e conceitos. 3. ed. Rio de Janeiro: Bertrand do Brasil, 1998.

NIMER, E. Climatologia do Brasil. Rio de Janeiro: IBGE, 1979.

OKA-FIORI, C.; CANALI, N. E. Geomorfologia da área do Parque Marumbi - Serra do Mar (PR). SIMPÓSIO SUL-BRASILEIRO DE GEOLOGIA, 3., 1987, Curitiba. Anais...

OKA-FIORI, C.; CANALI, N. E.; KOZCIAK, S. Mapeamento geomorfológico e hidrográfico do litoral sul do estado do Paraná. In: NEGRELLE, R. R. B.; LIMA, R. E. Meio ambiente e desenvolvimento do litoral do Paraná: subsídios à ação. Curitiba: NIMAD/UFPR, 2002.

PARANÁ. Secretaria de Estado do Meio Ambiente e dos Recursos Hídricos. Programa Floresta Atlântica. Mapeamento da Floresta Atlântica do Paraná. Relatório Final. Curitiba, 2002.

PARANÁ. Secretaria de Estado do Meio Ambiente e dos Recursos Hídricos. Programa Floresta Atlântica. Mapeamento geológico da região de ocorrência da Floresta Atlântica no Paraná. Curitiba: Sema/Mineropar, 2003. CD-ROM.

PAULA, E. V.; CUNICO, C. Organização dos dados geográficos da Baía de Antonina e Bacias de Drenagem. Relatório técnico Programa CAD, terminais portuários da Ponta do Felix. Antonina, 2005.

REBELO, A. M. A.; CAMPOS, L. E. G.; REIS, D. T. Origem dos metais pesados e arsênio na Baía de Antonina (PR). Relatório técnico Programa CAD, terminais portuários da Ponta do Felix. Antonina, 2005.

SALAMUNI, R.; ROCHA, A. L. Geologia da região do Rio Cachoeira. Antonina (PR). Relatório inédito. Curitiba, 2002.

SORRE, M. A. Adaptação ao meio climático e biossocial geografia psicológica. In: MEGALE, J. F. (Org.). Max Sorre. São Paulo: Ática, 1984. (Grandes Cientistas Sociais, 46). 